\title{
Qualidade do leite produzido no semiárido de Minas Gerais
}

\author{
Quality of milk produced in the semiarid area of Minas Gerais State
}

\section{Edivânia Souza Zeferino ${ }^{1}$, Cinara da Cunha Siqueira Carvalho ${ }^{1 *}$, Luciana Albuquerque Caldeira Rocha ${ }^{1}$, José Reinaldo Mendes Ruas² e Sidnei Tavares dos Reis ${ }^{3}$}

Recebido em 02/10/2015 / Aceito em 13/09/2016

\section{RESUMO}

O setor de produção de leite no Brasil, apresenta problemas de qualidade e por isso perde em competitividade. Assim, o Ministério da Agricultura, Pecuária e Abastecimento, publicou em 30 de dezembro de 2011 a Instrução Normativa 62 (IN 62), na qual fixa valores para os parâmetros físicoquímicos, Contagem Bacteriana Total (CBT), Contagem Células Somáticas (CCS), além de propor um controle de resíduos inibidores e antibióticos no leite. Em virtude da implantação dessa normativa, objetivou-se com este trabalho avaliar a qualidade do leite cru produzido em propriedades na região do semiárido mineiro bem como o perfil das instalações e dos produtores de leite. Foram coletadas 92 amostras de leite cru e encaminhadas para análise na clínica do leite e no laboratório da indústria. Foram realizadas análises físico-químicas, contagem de células somáticas, contagem bacteriana total e teste de resíduo de antibióticos. Os dados referentes ao perfil dos produtores, às condições sanitárias e à tipologia das edificações foram obtidos por meio de questionários e, posteriormente, foram apresentados em porcentagem. Os valores das propriedades físico-químicas, ao serem submetidos ao teste qui-quadrado, revelaram concordância com a legislação vigente. Os parâmetros CCS, CBT e índice crioscópico apresentaram valores acima dos permitidos pela legislação. A falta de refrigeração do leite foi o parâmetro que apresentou maior descumprimento com relação à IN 62.

\begin{abstract}
The Brazilian dairy industry has trouble with milk quality and, therefore, it loses competitiveness. Thus, the Ministry of Agriculture, Livestock and Supply, published on December 30, 2011, the Normative Instruction 62, in which fixed values for the physical and chemical parameters, somatic cell counts (SCC), composition and total bacterial counts (TBC) as well proposing controlling inhibitors and antibiotic residues in milk. Due to the implementation of this rule, the aim of this work was to evaluate the quality of raw milk produced on the properties in the semiarid region of Minas Gerais state as well as the profile of the installations and dairy farmers. We collected 92 samples of raw milk and sent them for analysis in milk clinical and industry laboratory. Physical and chemical analysis, somatic cell count, total bacterial count and antibiotic residue test were performed. The data relating to the profile of producers, sanitary conditions and the types of buildings were obtained by means of questionnaires and the data was presented as a percentage. The values of the physical-chemical properties were submitted to the chi-square test and it was found that they are consistent with current legislation. The SCC parameters, TBC and cryoscopic index showed values above those allowed by law. The lack of milk cooling was the parameter with the highest non-compliance with respect to IN 62 .
\end{abstract}

KEYWORDS: hygiene, instruction, production.

PALAVRAS-CHAVE: higiene, Instrução Normativa, produção.

\footnotetext{
${ }^{1}$ Universidade Estadual de Montes Claros, Janaúba, MG, Brasil.

${ }^{2}$ Empresa de Pesquisa Agropecuária de Minas Gerais, Janaúba, MG, Brasil.

${ }^{3}$ Universidade Federal de Sergipe, Nossa Senhora da Glória, SE, Brasil.

*Autor para correspondência <cinarasiqueira@yahoo.com.br>
} 


\section{INTRODUÇÃO}

O leite é um dos alimentos mais completos e essenciais para o desenvolvimento do corpo humano por possuir em sua composição todos os nutrientes em quantidades consideráveis. Apesar de seus diversos benefícios para a saúde humana e animal, o leite, quando retirado, manuseado ou armazenado de forma incorreta, torna-se um propício meio de cultura para o desenvolvimento de microrganismos indesejáveis (SILVA et al. 2008).

Neste sentido, entende-se que a ausência de sala de ordenha apropriada, temperatura inadequada de armazenamento, condutas higiênicas insatisfatórias durante sua manipulação aliadas a condições precárias de higiene do local, equipamentos e utensílios inapropriados vêm sendo considerados como uma das principais razões para a perda de qualidade do leite no Brasil.

Diante deste cenário,o Ministério daAgricultura, Pecuária e Abastecimento (MAPA 2011), por meio do Programa Nacional de Melhoria da Qualidade do Leite (PNMQL), publicou em 30 de dezembro de 2011 a IN 62, que propõe um controle mais sistemático de parasitas, mastites, brucelose e tuberculose, além de estabelecer valores intermediários entre a citação atual e a exigida pela IN 51, para contagem de células somáticas (CCS), contagem bacteriana total (CBT), composição química e pesquisa de resíduos inibidores e antibióticos no leite.

Embora a aplicação da legislação tenha o propósito de melhorar a qualidade do leite produzido no Brasil, acredita-se que há ainda a necessidade de se investir em formação técnica dos produtores, por meio de treinamento, principalmente aqueles de agricultura familiar, cujo sustento da família está baseado na produção de leite (MARTINS et al. 2008). A preocupação com os pequenos produtores se fundamenta no fato de que a maioria não possui condições de se adequar às normas propostas nem de adquirir equipamentos exigidos para incorporar as mudanças (ANJOS et al. 2004, BATTAGLINI et al. 2013).

Esta é a realidade da região do semiárido mineiro, onde são produzidos anualmente 261 milhões de litros de leite, cerca de $4 \%$ da produção estadual, sendo os pequenos produtores responsáveis por $51 \%$ dessa produção (SEAPA 2012). Esse tipo de produção é caracterizado por unidade familiar, por ser oriundo de propriedades pequenas, abaixo de 50 ha, e com um nível tecnológico baixo que dificulta uma produção de leite de melhor qualidade.

Considerando a importância que o leite possui na alimentação humana, economia e sustento da agricultura familiar do semiárido mineiro, objetivouse com este trabalho caracterizar a qualidade do leite cru produzido por meio da verificação do manejo, das condições estruturais e de higiene das instalações, do nível de percepção dos produtores com relação à adoção das novas Instruções Normativas bem como a análise dos parâmetros físico-químicos do leite e a sua adequação aos valores preconizados pela IN 62 .

\section{MATERIAL E MÉTODOS}

A coleta de dados ocorreu em 92 propriedades rurais pertencentes aos municípios de Porteirinha, Mato Verde e Monte Azul, localizados na região Norte de Minas Gerais. Essas propriedades são fornecedoras de leite para uma indústria situada no território da Serra Geral, MG, cujo volume médio diário é de 8.000 litros e que está sob a inspeção do IMA (Instituto Mineiro Agropecuária).

O processo de ordenha foi acompanhado para observação dos procedimentos de manejo e higiene adotados pelo produtor e, ao final, coletavam-se as amostras de leite em cada propriedade, em recipientes estéreis, identificados e acondicionados em caixa térmica com gelo reciclável até o momento de entrega aos laboratórios da clínica do leite (ESALQ/USP) e da indústria, onde o leite era beneficiado.

Os procedimentos de coleta e envio de amostras (tanque e latão) seguiram as recomendações do manual de instruções do laboratório clínica do leite, onde foram realizadas as seguintes análises: gordura, proteína, lactose, estrato seco total e desengordurado, índice crioscópio, Contagem de Células Somáticas (CCS), Contagem Bacteriana Total (CBT) e resíduo de antibiótico.

As coletas das amostras de leite no latão ocorreram no próprio estabelecimento rural, logo após a ordenha. As amostras do tanque particular foram coletadas no período de tempo similar ao do latão; no entanto, 10 minutos antes da retirada, o agitador do tanque era acionado para a homogeneização completa do leite. Em seguida, as amostras do tanque e latão, destinadas à caracterização físico-química foram transferidas para o frasco e acrescentada a pastilha de bronopol (2-bromo 2-nitro propano, 1,3-diol) para conservação até o momento das análises. 
Para a análise de CBT, coletou-se a amostra de leite no latão e no tanque particular. Cada amostra foi colocada em um frasco de coleta e em seguida foram adicionadas quatro gotas do conservante Azidiol, homogeneizado e armazenado em caixa térmica com a presença de gelo reciclável, para que a temperatura não ultrapassasse $3{ }^{\circ} \mathrm{C}$.

Para determinar a presença de inibidores em leite cru, as amostras foram homogeneizadas individualmente, transferidas para $o$ frasco esterilizado, congeladas e armazenadas em caixa térmica para o envio ao laboratório clínica do leite.

A determinação da CCS presentes no leite cru no tanque e no latão foi realizada no equipamento Somacount 300 que utiliza a metodologia de citometria de fluxo. A composição do leite cru (gordura, proteína, lactose, sólidos totais e índice crioscópio) no tanque e no latão foi verificada no equipamento Bentley $2000^{\circledR}$. A análise da contagem bacteriana total do leite cru (CBT) foi realizada através do equipamento Bactocount pela metodologia de citometria de fluxo. E a presença de inibidores em leite cru (ATB) foi averiguada a partir do uso do kit a Delvo Test, por meio de metodologia microbiológica.

As análises de alizarol foram realizadas diretamente nos postos de coleta e nas propriedades com amostras de leite e alizarina $70 \%$. A acidez Dornic de todas as amostras de leite foi determinada no laboratório da cooperativa, após a coleta de amostras de leite e seu posterior resfriamento em caixas de isopor e gelo reciclável.

No laboratório do laticínio foi realizado o teste de alizarol, com auxílio da pistola específica para o teste, que mistura partes iguais do alizarol e do leite analisado. $\mathrm{O}$ alizarol utilizado nos testes tinha concentração mínima exigida em legislação de $72 \%$ $\mathrm{v} / \mathrm{v}$ (volume/volume).

A acidez do leite foi analisada pelo método de Dornic (acidez titulável). Neste teste utilizou-se uma solução de hidróxido de sódio N/9 ou $0,11 \mathrm{~N}$, designada de soda Dornic, usando-se como indicador uma solução alcoólica de fenolftaleína a 1\%.

Juntamente com as coletas das amostras de leite, foi aplicado aos produtores um questionário para verificar o nível de percepção dos mesmos com relação à forma adequada de manejo e sanidade do rebanho, além do conhecimento e opinião no que se refere às Instruções Normativas do Ministério da Agricultura, Pecuária e Abastecimento.
Os dados obtidos por meio dos questionários foram compilados, analisados por meio de estatística descritiva e apresentados em forma de porcentagem. Os valores das propriedades físico-químicas foram submetidos ao teste qui-quadrado.

\section{RESULTADOS E DISCUSSÃO}

A respeito da aplicação dos questionários, verificou-se que a produção média de leite variou de 4,0 a 233,0 litros diários por propriedade, indicando grande heterogeneidade das propriedades em relação à produção de leite. Esta heterogeneidade está relacionada principalmente com a raça e a produtividade média por vaca em lactação.

De forma geral, as instalações onde ocorre a ordenha são de chão batido, abertas nas laterais e ausentes de equipamentos para limpeza e higienização dos tetos dos animais e das mãos do ordenhador.

Em $61 \%$ das propriedades, a alimentação dos animais foi baseada em pastagem constituída de Braquiária; em $38 \%$ das propriedades a alimentação foi principalmente de silagem de sorgo, e, em $1 \%$ era baseada em outros alimentos como o caroço e a torta de algodão, mandioca e palma forrageira. $\mathrm{O}$ fornecimento de concentrado e sal mineral foi verificado em $53 \%$ e $82 \%$, respectivamente, das propriedades analisadas, sendo que $40 \%$ do concentrado utilizado foi formulado na própria propriedade, e 13\% comprados de fábrica de ração.

A partir dos dados levantados quanto ao nível tecnológico adotado nas unidades de produção leiteira para o sistema de ordenha e refrigeração do leite, observou-se que em $100 \%$ das propriedades o sistema de ordenha empregado é o manual. A ordenha manual, quando tomados os cuidados de ordenha higiênica, não implica baixa qualidade do leite. Da mesma forma segundo BEHMER (1999), a ordenha mecânica possibilita a obtenção de leite com maior pureza, no entanto, não indica necessariamente uma melhoria na qualidade do leite, já que suas tubulações podem representar fontes adicionais de contaminação caso não ocorra uma higienização adequada (KLUNGEL et al. 2000).

Para a refrigeração do leite, segundo a IN 62, aceitam-se dois sistemas de refrigeração, o de imersão e o de expansão, que devem resfriá-lo a $7^{\circ} \mathrm{C}$ em 3 horas e $4{ }^{\circ} \mathrm{C}$ em 3 horas, respectivamente. Somente $50 \%$ dos produtores cumprem as exigências e estão dentro dos padrões da IN 62 , sendo que deste total, $45 \%$ possuem 
tanque de resfriamento do leite e $45 \%$ entregam leite em tanques comunitários situados próximos à propriedade. Os demais produtores entregam leite no laticínio em caminhão, carro ou moto.

Esses dados demonstram que ainda existe falta de investimento em tecnologia no setor leiteiro, influenciada, provavelmente, pelos baixos preços pagos pelo leite, desconhecimento da legislação, elevado custo de produção em decorrência de prolongadas secas na região, o que diminui o aporte financeiro a esses investimentos. Desse modo, tornamse necessários a conscientização e o investimento em tecnologia no setor leiteiro, uma vez que a temperatura de refrigeração exerce grande influência na contagem bacteriana (MARSHALL 1991), e, caso não seja feito um controle efetivo de higienização durante todo o processo, o leite sofre perda de qualidade (MARTINS et al. 2004).

Nesta pesquisa, foi constatado que $36 \%$ dos produtores utilizavam práticas de higienização no momento da ordenha, sendo que desse total, $35 \%$ realizavam a lavagem dos tetos com água sem nenhum tratamento e $1 \%$ fazia o tratamento da água com cloro. Verificou-se também que $100 \%$ dos produtores não desprezavam os três primeiros jatos de leite, e 91\% filtravam em filtros de plásticos específicos para a função (comercializados em lojas agropecuárias). O leite era filtrado ao passar para o tanque de resfriamento ou antes de entregar à indústria.

A água utilizada tanto para o consumo dos animais quanto para as práticas de higiene nas propriedades também pode ser um fator importante de contaminação, visto que ela pode ser veículo de agentes patogênicos para seres humanos e para animais (AMARAL 2010). Neste estudo, em 86\% das propriedades a água utilizada é proveniente de rio e $14 \%$ de poços, sendo que somente em $1 \%$ das propriedades o tratamento é feito com cloro.

A Instrução Normativa 62 determina que a água destinada à produção de leite e à indústria de laticínios deve ser tratada e clorada, além de ser aprovada em sua condição bacteriológica e físico-química.

A carga microbiana é um dos principais indicadores da qualidade da água na propriedade leiteira. Utilizar água com qualidade microbiológica fora dos padrões pode levar à contaminação de equipamentos de ordenha e de resfriamento, comprometendo, consequentemente, a qualidade do leite pelo aumento da contagem bacteriana total (JOÃO et al. 2011). Além disso, a água não tratada pode veicular agentes causadores de mastite, principalmente Staphylococcus aureus.

De acordo com os dados identificados na análise dos questionários, constatou-se que 55\% dos produtores afirmaram que já ocorreram casos de mamite no rebanho, sendo que do total de produtores entrevistados, somente $18 \%$ já realizaram o teste da caneca de fundo preto ou CMT (California Mastitis Test) para detecção da doença no rebanho ou na hora da compra. Quando indagados sobre a utilização de antibióticos, $57 \%$ dos produtores afirmaram realizar tratamento com antibióticos nas vacas em lactação com sintomas deste problema sem realização de nenhum teste de detecção da doença ou orientação técnica. Este é um fato preocupante, porque pode ocasionar a presença de resíduos de antibióticos no leite e a resistência das bactérias.

A partir das amostras de leite analisadas em laboratório, observou-se que somente $1 \%$ apresentou presença de antibióticos no leite. A conscientização dos produtores é fundamental para prevenção de resíduos desses medicamentos em leite, uma vez que estes resíduos podem causar vários efeitos indesejáveis, como seleção de cepas bacterianas resistentes no ambiente e no consumidor, hipersensibilidade e possível choque anafilático em indivíduos alérgicos a essas substâncias, desequilíbrio da flora intestinal, além de efeito teratogênico (HILLERTON et al. 1999, VAN SCHAIK et al. 2002, NERO et al. 2007).

No que diz respeito à vacinação, todos os proprietários afirmaram que os animais são vacinados contra a febre aftosa e brucelose, o que foi confrontado e confirmado a partir dos dados fornecidos pelo laticínio do qual fazem parte.

No teste do alizarol a $72{ }^{\circ} \mathrm{GL}$ foi observado que $79 \%$ das amostras apresentaram resultados negativos, e $21 \%$ apresentaram resultados positivos. Segundo a IN 62, as amostras de leite cru não devem precipitar na presença do alizarol ou na prova do álcool, sendo estas consideradas como positivas.

Quanto à acidez titulável, constatou-se que 78\% (Tabela 1) das amostras de leite estavam de acordo com a legislação brasileira, que recomenda o recebimento de leite cru refrigerado com acidez variando de 0,14 a $0,18 \mathrm{~g}$ de ácido lático/100 mL de leite. Além disso, 7\% das amostras revelaram alcalinidade, com valores abaixo do preconizado pela IN 62, e 15\% das amostras se encontravam ácidas, com valores acima do limite preconizado pela legislação.

Com relação às análises da composição 
Tabela 1 - Porcentagem de amostras de leite para valores de Acidez titulável, de acordo com a IN 62, Brasil. Table 1 - Percentage values of milk samples for titratable acidity, according to IN 62, Brazil.

\begin{tabular}{cc}
\hline Acidez titulável, g ácido láctico por $100 \mathrm{~mL}$ & Porcentagem de amostras \\
\hline Abaixo de $0,14 \mathrm{~g}$ & $7 \%$ \\
Entre 0,14 a $0,18 \mathrm{~g}$ & $78 \%$ \\
Acima de $0,18 \mathrm{~g}$ & $15 \%$ \\
\hline
\end{tabular}

do leite, verificou-se que a maioria das amostras encontra-se dentro dos padrões preconizados pela IN 62. Conforme demonstrado pela Tabela 2, a média de gordura no leite foi de $3,6 \%$ (sendo o valor mínimo encontrado de $1,6 \%$ e o máximo de 5,6\%). Do total de amostras, $6 \%$ não apresentaram o mínimo de 3,0\% de gordura no leite, exigido pela legislação. A gordura é o componente do leite de concentração mais variável, geralmente, o primeiro a sofrer alterações diante de qualquer fator de origem ambiental, fisiológico ou genético. Além disso, a determinação da gordura do leite contribui para a verificação da integridade em investigações de fraudes.

Com relação à proteína, a média encontrada foi de 3,04\%, sendo que o teor variou de 2,26 a $3,82 \%$. Das amostras analisadas, verificou-se que $15 \%$ estavam com os valores abaixo de $2,9 \%$, valor estabelecido pela IN 62.

O percentual de Extrato Seco Desengordurado (ESD) teve uma variação muito menor quando comparado aos teores de gordura e proteína. A partir dos resultados demonstrados na Tabela 2 , verifica-se que a média encontrada foi de $8,67 \%$. A IN 62 preconiza um valor mínimo de $8,4 \%$, e $17 \%$ das amostras analisadas demonstraram resultados abaixo do preconizado. As determinações de ST e ESD são análises importantes na rotina dos laticínios principalmente porque é uma forma de prever rendimentos industriais.

Com relação aos demais componentes, CBT, CCS e índice crioscópico (IC), foi constatado maior variação entre as médias quando comparados os demais componentes, conforme verificado na Tabela 3.

O índice crioscópico apresentou média de $-0,538{ }^{\circ} \mathrm{H}$. Do total analisado, constatou-se que $26 \%$ das amostras estavam fora dos padrões exigidos pela IN 62 , indicando a presença de água. Esse fato verificado no campo pode ser resultante de uma provável adulteração intencional ou acidental em função de resíduo de água no fundo do tanque ou da leiteira. Este parâmetro é de suma importância, uma vez que a água pode ser fonte de agentes contaminantes ao leite, além de afetar na sua composição físico-química.

Comparando os resultados das análises de CBT no leite com os padrões exigidos pela IN 62, constatouse que $5 \%$ dos produtores estão em desacordo com

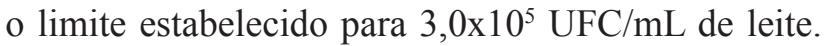
A média encontrada foi $2,990 \times 10^{5} \mathrm{UFC} / \mathrm{mL}$ de leite, sendo que as amostras variaram de $4 \times 10^{5} \mathrm{UFC} / \mathrm{mL}$ a 9,9x10 $0^{6} \mathrm{UFC} / \mathrm{mL}$. Esses resultados demonstram que, apesar da deficiência e simplicidade das instalações, do sistema de limpeza e da higienização, o número de amostras fora dos padrões exigidos pela legislação atual é considerado baixo.

Das amostras avaliadas $23 \%$ apresentaram

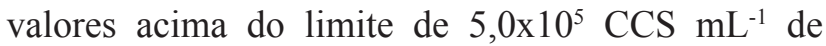
leite. A média encontrada foi de $4,81 \times 10^{5} \mathrm{CCS} \mathrm{mL}^{-1}$

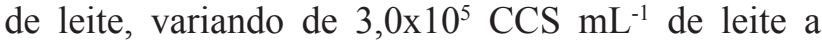
$3,798 \times 10^{6} \mathrm{CCS} \mathrm{mL}^{-1}$ de leite.

A CCS é um parâmetro de alta relevância para o produtor porque indica o estado sanitário das glândulas mamárias das vacas, podendo sinalizar perdas significativas de produção e alterações da qualidade do leite (HARMON 1994). Para a indústria, diminui a qualidade, o rendimento de fabricação de diversos derivados lácteos, bem como o tempo de prateleira (GUERREIRO et al. 2005).

A contagem de células somáticas constitui um dos principais desafios da melhoria da qualidade do leite a curto prazo, pois, normalmente, envolve custos elevados na adoção de ações corretivas, tais como descarte de animais, medicamentos para tratamento da mastite clínica e assistência técnica veterinária.

Embora haja muito que modificar no processo de produção do leite no Brasil para adequação às Instruções Normativas, nota-se que as mudanças já estão ocorrendo em virtude do pagamento extra que algumas indústrias têm feito aos produtores que cumprem as normativas. Dessa forma, os fornecedores sentem-se estimulados a modificar o processo a fim de receber um valor a mais no preço pago por litro.

Durante a realização deste trabalho, nenhuma das propriedades visitadas recebia da indústria esse "incentivo" para adequar o processo. No entanto, é 
Tabela 2 - Média das análises físico-químicas do leite cru refrigerado dos municípios localizados no semiárido de Minas Gerais.

Table 2 - Average physical and chemical analysis of raw cooled milk municipalities located in the semiarid area of Minas Gerais State.

\begin{tabular}{lrccc}
\hline \multicolumn{1}{c}{ Variáveis } & Média & Limite Mínimo & Limite Máximo & Desvio-padrão $(\sigma)$ \\
\hline Gordura $(\% \mathrm{~m} / \mathrm{m})$ & 4,00 & 1,61 & 5,58 & 0,72 \\
Proteína $(\% \mathrm{~m} / \mathrm{m})$ & 3,22 & 2,26 & 3,82 & 0,31 \\
ST $(\% \mathrm{~m} / \mathrm{m})$ & 12,67 & 10,33 & 14,77 & 0,92 \\
ESD $(\% \mathrm{~m} / \mathrm{m})$ & 8,67 & 6,43 & 9,41 & 0,39 \\
\hline
\end{tabular}

Tabela 3 - Média das análises de CCS, CBT e índice crioscópico do leite cru refrigerado dos municípios localizados no semiárido de Minas Gerais.

Table 3 - Average analysis the CCS, CBT and cryoscopic index of refrigerated raw milk from municipalities in the semiarid area of Minas Gerais State.

\begin{tabular}{lrccc}
\hline \multicolumn{1}{c}{ Variáveis } & Média & Limite Mínimo & Limite Máximo & Desvio-padrão ( $)$ \\
\hline IC $\left({ }^{\circ} \mathrm{H}\right)$ & $-0,54$ & 477 & 552 & 60,85 \\
CBT $(\mathrm{UFC} / \mathrm{mL})$ & 299,13 & 04 & 9999 & 1236,58 \\
$\mathrm{CCS}(\mathrm{x} \mathrm{mil} / \mathrm{ml})$ & 481,72 & 30 & 3798 & 581,92 \\
\hline
\end{tabular}

notório que a preocupação com a higiene no instante da ordenha tem-se refletido em resultados positivos no que se refere à qualidade do leite. Contudo, ainda são necessárias maiores ações de extensão para aumentar o nível de conhecimento e conscientização do produtor de leite no Norte de Minas Gerais.

\section{CONCLUSÃO}

O leite cru avaliado apresentou-se em desacordo com a legislação vigente. Os parâmetros de qualidade e higiene do leite, como a CCS e índice crioscópico, apresentaram valores acima dos permitidos pela legislação. A refrigeração do leite foi o parâmetro que apresentou maior descumprimento com relação à IN 62.

\section{REFERÊNCIAS}

AMARAL LA. 2010. A água na produção de leite. Versão eletrônica. Disponível http://cienciadoleite. com.br/noticia/2870/a-agua-na-producao-doleite?busca2=\%C3\%81GUA Acesso: 03 fev. 2013.

ANJOS FS et al. 2004. Agricultura familiar e políticas públicas: o impacto do PRONAF no Rio Grande do Sul. Revista de Economia e Sociologia Rural 42: 529-548. BATTAGLINI APP et al. 2013. Difusão de boas práticas e caracterização de propriedades leiteiras. Archivos de Zootecnia 62: 151-154.

BEHMER MLA. 1999. Tecnologia do leite: leite, queijo, manteiga, caseína, iogurte, sorvetes e instalações. 13.ed. São Paulo, SP: Nobel. 320p.

GUERREIRO PK et al. 2005. Qualidade microbiológica de leite em função de técnicas profiláticas no manejo de produção. Ciência e Agrotecnologia e Agrotecnologia 29: 216-222.

HARMON RJ. 1994. Physiology of mastitis and factors affecting somatic cell counts. Journal of Dairy Science 77: 2103-2112.

HILLERTON JE et al. 1999. Detection of antimicrobial substances in individual cow and quarter milk samples using Delvotest microbial inhibitor tests. Journal of Dairy Science 82: 704-711.

JOÃO JH et al. 2011. Qualidade da água utilizada na ordenha de propriedades leiteiras do Meio Oeste Catarinense, Brasil. Revista de Ciências Agroveterinárias 10: 9-15.

KLUNGEL GH et al. 2000. The effect of the introduction of automatic milking systems on milk quality. Journal of Dairy Science 83: 1998-2003.

MAPA - Ministério da Agricultura, Pecuária e Abastecimento. 2011. Departamento de Inspeção de Produtos de Origem Animal. Instrução Normativa 62. Aprova e oficializa o Regulamento Técnico de Identidade e Qualidade do Leite e Leite Pasteurizado. Diário Oficial Da União, 29 de dezembro de 2011. Disponível em: http:// www.jusbrasil.com.br/diarios/33395065/dou-secao-1-30- 
12-2011-pg-6. Acesso em: 06 jun. 2012.

MARSHALL J. 1991. Differential diagnosis of high TBC. In Practice 13: 198-201.

MARTINS ML et al. 2004. Detecção de proteases bacterianas em leite por métodos imunológicos. Revista do Instituto de Laticínios Cândido Tostes 59: 61-61.

MARTINS MEP et al. 2008. Qualidade de leite cru produzido e armazenado em tanques de expansão no estado de Goiás. Ciência Animal Brasileira 9: 1152-1158.

NERO LA et al. 2007. Resíduos de antibióticos em leite cru de quatro regiões leiteiras no Brasil. Ciência e Tecnologia de Alimentos 27: 391-393.

SEAPA - Secretaria de Estado de Agricultura, Pecuária e Abastecimento de Minas Gerais. 2012. Produção de leite em Minas Gerais será recorde. Disponível em: http://www. agricultura.mg.gov.br/ajuda/story/692-producao-de-leiteem-minas-gerais-sera-recorde. Acesso em: 02 fev. 2013.

SILVA MCD et al. 2008. Caracterização microbiológica e físico-química de leite pasteurizado destinado ao programa do leite no Estado de Alagoas. Revista de Ciência e Tecnologia de Alimentos 28: 226-230.

VAN SCHAIK $G$ et al. 2002. Trends in somatic cells counts, bacterial counts, and antibiotic residue violations in New York State during 1999-2000. Journal of Dairy Science 85: 782-789. 